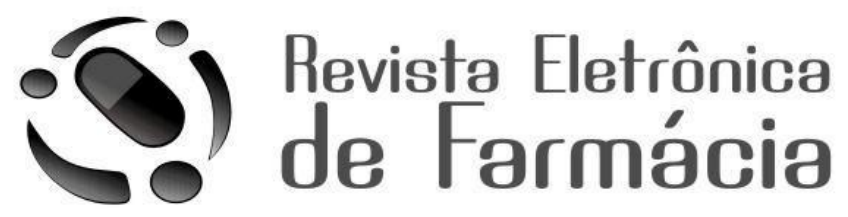

REF - ISSN 1808-0804 Vol. X (3), 30 - 42, 2013.

\title{
CONDIÇÕES HIGIÊNICO-SANITÁRIAS DE SALADA DE VEGETAIS SERVIDAS EM TRÊS RESTAURANTES SELF-SERVICEEM MUNICÍPIO DO INTERIORDE SANTA CATARINA, BRASIL
}

HYGIENIC AND SANITARY CONDITIONS OF VEGETABLE SALAD SERVED IN THREE RESTAURANTS IN SELF-SERVICE WITHIN THE MUNICIPALITY OF SANTA CATARINA, BRAZIL

CONDICIONES HIGIÉNICAS Y SANITARIAS DE ENSALADA DE VEGETALES SERVIDO EN TRES RESTAURANTES EN AUTOSERVICIO EN EL MUNICIPIO DE SANTA CATARINA, BRASIL

\author{
${ }^{1}$ Karina Zanoni, ${ }^{2}$ Jane Mary Lafayette Neves Gelinski \\ ${ }^{1}$ Farmacêutica pela Universidade do Oeste de Santa Catarina \\ 2Doutora em Ciências dos Alimentos pela Universidade de São Paulo
}

Enviado em 08/01/2013, Aceito em 14/06/2013

Resumo: O crescimento econômico e a globalização têm influenciado a mudança dos hábitos dos brasileiros, inclusive os alimentares. A procura por refeições fora de casa cresce cada vez mais. Entre as opções para quem busca rapidez no atendimento, variedade no cardápio e baixo custo, estão os restaurantes do tipo self service. Mesmo adeptos desses serviços, os consumidores também buscam uma alimentação saudável. Nesta pesquisa foram avaliadasas condições higiênico-sanitárias de saladas de vegetais 
ZANONI, K.; GELINSKI, J. M. L. N. Revista Eletrônica de Farmácia Vol. X (3), 30 - 42, 2013.

servidas em três restaurantes self service de uma cidade do interior de Santa Catarina.Porções de $200 \mathrm{~g}$ de saladas de vegetais crus frescos e prontos para consumo foram obtidas durante 5 dias numa mesma semana em cada restaurante, totalizando 15 coletas. Em quatro, das cinco amostragens, 100\% das amostras estavam impróprias para consumo, ou seja, em desacordo com a legislação vigente para contagem de coliformes totais e coliformestermotolerantes. Escherichia coli foi confirmada para um dos restaurantes, mas Salmonellasp. não foi detectada em nenhuma das amostras.Para evitar o risco de DTA' se considerando que a contaminação pode ocorrer em todas as etapas de preparo de alimentos, é necessário que os restaurantesadotem medidas rigorosas de higiene, bem como boas práticas de processamento e disposição do alimento ao consumidor.

Palavras-chave: Restaurantes, Doenças transmitidas por alimentos.

Abstract: Economic growth and globalization have influenced the changing habits of Brazilians, including food. The demand for food away from home grows increasingly. The self-service restaurants are among the options for those seeking fast service, variety on the menu, and low cost. Even supporters of such services, consumers also seek a healthy diet. In this study we evaluated the sanitary conditions of vegetable salads served in three self-service restaurants in a city in the interior of Santa Catarina. About $200 \mathrm{~g}$ of fresh salads and raw vegetables ready for consumption were obtained for 5 days in the same week every restaurant, totaling 15 samples. In four of the five samples, $100 \%$ of the samples were unfit for consumption, i.e. at variance with the law for fecal coliform. Escherichia coliwas confirmed for one of the restaurants, but Salmonella sp. was not detected in any sample. To avoid the risk of DTA's considering that contamination can occur at all stages of food preparation, it is necessary that restaurants adopt strict measures of hygiene and good processing practices and provision of food to the consumer.

Keywords: Restaurants,Foodborneillness.

Resumem: El crescimiento económico y laglobalizaciónhaninfluidoenlos hábitos de losbrasileños, incluidoslos dealimentación. La demanda de alimentos fueradelhogarcrece cada vez más. Entre lasopciones para aquellos que buscanunservicio rápido, variedadesenelmenú y bajo costo, sonlos restaurantes de autoservicio. Incluso lospartidarios de tales servicios, los consumidores buscantambién una dieta saludable. En este estudio se evaluaronlas condiciones sanitarias de lasensaladas de verduras servidas entres restaurantes de autoservicioen una ciudaddel interior de Santa Catarina. Porciones 
ZANONI, K.; GELINSKI, J. M. L. N. Revista Eletrônica de Farmácia Vol. X (3), 30 - 42, 2013.

de $200 \mathrm{~g}$ de ensaladasdevegetalesfrescos y crudoslistos para el consumo se obtuvieron durante 5 díasen cada restaurante, en total de 15 muestras y 90 analisis.

Encuatromuestras $100 \%$ eran no adecuados para el consumo, es decir, endesacuerdocon la ley para coliformes totales y coliformes fecales. Escherichia colifue confirmado paraun de los restaurantes, pero Salmonellasp. no se detectóenningunamuestra. Para evitar elriesgo de ETAs, considerando que la contaminaciónpuedeocurriren todas las etapas de preparación de los alimentos, es necesario que los restaurantes adopten medidas estrictas de higiene y buenasprácticas de elaboración y elsuministro de alimentos al consumidor.

Palabras claves: Restaurantes, Enfermedades Transmitidas por los Alimentos.

\section{INTRODUÇÃO}

O crescimento econômico e a globalização têm influenciado a mudança dos costumes dos brasileiros, inclusive no que se refere aos hábitos alimentares. Esse modo contemporâneo somado a falta de tempo e à disponibilidade de opções de alimentação fora do ambiente doméstico, leva os consumidores a procurar cada vez mais serviços de alimentação fora de casa ${ }^{(1)}$. Os restaurantes do tipo self-service procuram acompanhar essa tendência e sua expansão é cada vez maior mesmo em pequenas cidades do interior do sul do Brasil. Tal crescimento é explicado pelo fato de que esse tipo de serviço oferece vantagens ao consumidor como uma grande variedade de opções de cardápio, rapidez no atendimento e custos mais acessíveis ${ }^{(2)}$. Os consumidores também têm buscadohábitos saudáveis e estão cada vez mais interessados por alimentos frescos e com baixoteor calórico. Esses alimentos na forma in natura são muito consumidos e tem elevado valor nutritivo, porém se as condições higiênico-sanitárias não forem adequadas, podem tornar-se veículos transmissíveis de microrganismos patogênicos para 0 homem ${ }^{(3)}$.A qualidade da matéria prima, o tempo de descongelamento e cozimento, o aproveitamento de sobras alimentares, os equipamentos e utensílios utilizados no preparo e os próprios manipuladores de alimentos são também importantes fontes de microrganismos ${ }^{(1)}$. Para os profissionais da área de alimentação, esses fatores aliadosao tempo de exposição dos alimentos em temperaturas inadequadasé ainda mais preocupante $^{(4)}$.

Embora os consumidores de modo geral estejam preocupados com a qualidade nas refeições, há falta de educação alimentar que permita a esse público avaliar as condições dos alimentos antes de consumi-los. Segundo Pintoet al. ${ }^{(5)}$,grande parte dos surtos de doenças de origem alimentar são causadas por alimentos preparados 
ZANONI, K.; GELINSKI, J. M. L. N. Revista Eletrônica de Farmácia Vol. X (3), 30 - 42, 2013.

em serviços de alimentação. Nesses estabelecimentos, rigorosas práticas de higiene devem ser adotadas a fim de evitar o risco de doenças transmitidas por alimentos. As DTA's(Doenças Transmitidas por Alimentos) podem causar anorexia, náuseas, vômitos e/ou diarréia. As DTA'sestão relacionadas à ingestão de alimentos ou água contaminados por microorganismos, vírus, toxinas, príons, agrotóxicos, produtos químicos e metais pesados. Os sintomas vão desde leve dor abdominal até quadros extremamente sérios com desidratação grave, diarréia sanguinolenta, insuficiência renal aguda e insuficiência respiratória(6).

Salmonellasp.eEscherichia coli patogênica estão entre os patógenos mais freqüentemente associados a DTA's, além deClostridium perfringens, a toxinas deStaphylococcus aureus eBacilluscereus ${ }^{(7,8)}$.Salmonellasp.é uma bactéria responsável por intoxicações alimentares graves, podendo atingir vários órgãos e causando lesões. A transmissão desse patógeno pode ocorrer em vegetais contaminados com esterco $^{(7,8)}$. A presença de Escherichia coli em alimentos é um indicador de possível contaminação fecal por estar presente em grande quantidade no trato gastrointestinal do homem ${ }^{(6,9)}$. Conforme indica a Secretaria de Vigilância em Saúde, as ocorrências de DTA's podem serminimizadas se houver por parte de manipuladores e consumidoreso cuidado ao usar águas de fontes não confiáveis, só consumirem alimentos seguros, separarem alimentos crus de alimentos cozidos, lavarem as mãos com frequencia e nãodeixarem alimentos cozidos à temperatura ambiente por mais de duas horas ${ }^{(6)}$.

Dados do Ministério de Saúde constatam que de 1999 a 2008 no Brasil foram notificados 6.062 surtos de DTA's envolvendo 117.330 pessoas doentes e 64 óbitos $^{(10)}$.

Já em Santa Catarina neste mesmo período foram registrados 530 casos de DTAs. No Brasil entre 1999 à 2008 legumes e verduras foram os responsáveis por 114 surtos de DTA's relatados.No mesmo período, entre os locais de ocorrência de surtos, as residências ficaram em primeiro lugar com $45,2 \%$, seguidas pelos restaurantes com $19,7 \%$ dos casos de surtos e em terceiro lugar uma surpresa, as instituições de ensino que atingirtam $10,7 \%$ dos surtos ${ }^{(10)}$.

Com base nestes dados, e pelo pouco registro de trabalhos que avaliem a qualidade de vegetais frescos comercializados em restaurantes, o objetivo deste trabalho foi avaliar a qualidade microbiológica de salada de vegetais servidas em três restaurantes localizados em cidade do interior de Santa Catarinae analisaras condições higiênico-sanitarias desses produtos frescos prontos para consumo disponibilizados aos comensais.

\section{MATERIALE MÉTODOS}


ZANONI, K.; GELINSKI, J. M. L. N. Revista Eletrônica de Farmácia Vol. X (3), 30 - 42, 2013.

\section{Local das coletas}

Foram selecionados três restaurantes tipoself-service, localizados em pontos estratégicos de município do interior de Santa Catarina, Brasil: dois localizados na região central da cidade e um terceiro localizado em bairro da periferia.Os restaurantes denominados neste estudo $A, B$ e $C$ servem em torno de 40-60refeições diariamente.

\section{Caracterização e coleta das}

amostras

Foiobtido em cada coleta/dia/restaurante de $200 \mathrm{~g}$ a $230 \mathrm{~g}$ de saladas de vegetais crus, sendo que para cada tipo de verdura padronizou-se para uma coleta de 3sub-porçõesfrescas de cada item constante no cardápio do restaurante para o buffet de verduras cruas. As amostra foram obtidasa partir de coletas embuffets durante horário de almoço (12 às $14 \mathrm{~h}$ ). Foram realizadas cinco coletas para cada um dos restaurantes durante cinco dias seguidos (de segunda a sexta-feira). As amostras foram acondicionadas em bandejas de alumínio fechadas e transportadas,sobe refrigeração,até 0 laboratório da Universidade para análise microbiológica visando ao processamento imediato. Todos os meios de cultura (Oxoid, Inglaterra ou HiMedia, India) e reagentes analíticos foram preparados conforme instrução de cada fabricante.

O quadro 1 descreve as amostras obtidas em cada restaurante durante a semana de coleta.

Quadro 1. Descrição das amostras de saladas de vegetais coletadas em cada um dos três restaurantes self-service.

\begin{tabular}{|c|c|c|c|}
\hline \multirow{2}{*}{ DIAS } & \multicolumn{3}{|c|}{$\begin{array}{c}\text { PORÇÕES DE SALADA }(200 \mathrm{~g}-230 \mathrm{~g}) \text { DE VEGETAIS EM } \\
\text { CADA COLETA POR RESTAURANTE }\end{array}$} \\
\hline & A & B & C \\
\hline Segunda- feira & $\begin{array}{l}\text { Alface, Beterraba } \\
\text { Pepino }\end{array}$ & $\begin{array}{c}\text { Rúcula, Beterraba } \\
\text { Couve- flor }\end{array}$ & $\begin{array}{l}\text { Repolho, Tomate, } \\
\text { Alface, Cenoura }\end{array}$ \\
\hline Terça- feira & $\begin{array}{l}\text { Alface, Beterraba } \\
\text { Cenoura }\end{array}$ & $\begin{array}{l}\text { Alface, Rúcula } \\
\text { Beterraba }\end{array}$ & $\begin{array}{l}\text { Pepino, Cenoura, } \\
\text { beterraba }\end{array}$ \\
\hline Quarta- feira & $\begin{array}{l}\text { Repolho, Couve- flor } \\
\text { Alface, Beterraba }\end{array}$ & $\begin{array}{l}\text { Tomate, Cenoura } \\
\text { Agrião }\end{array}$ & $\begin{array}{l}\text { Pepino, Tomate, } \\
\text { Repolho, Pimentão }\end{array}$ \\
\hline Quinta- feira & $\begin{array}{c}\text { Pepino, Cenoura } \\
\text { Beterraba }\end{array}$ & $\begin{array}{c}\text { Repolho, Pimentão } \\
\text { Couve- flor }\end{array}$ & $\begin{array}{l}\text { Alface, Repolho, } \\
\text { Cenoura }\end{array}$ \\
\hline Sexta- feira & $\begin{array}{l}\text { Beterraba, Cenoura } \\
\text { Alface }\end{array}$ & $\begin{array}{l}\text { Tomate, Alface, } \\
\text { rúcula, Couve-flor }\end{array}$ & $\begin{array}{l}\text { Pepino, Tomate, } \\
\text { Beterraba }\end{array}$ \\
\hline
\end{tabular}

\section{Análises microbiológicas}


ZANONI, K.; GELINSKI, J. M. L. N. Revista Eletrônica de Farmácia Vol. X (3), 30 - 42, 2013.

As análises microbiológicas foram determinadascom base nos padrões microbiológicos sanitários para alimentos da Agência Nacional de Vigilância Sanitária-Anvisa ${ }^{(11)}$ : a) Determinação do número mais provável (NMP) de Coliformes totais (CT): são um subgrupo da Família Enterobacteriaceaecapaz de fermentar a lactose com produção de gás, em até $48 \mathrm{~h}$ à $35^{\circ} \mathrm{C}^{(8)}$; b) Determinação do NMP de Termotolerantes à $45^{\circ} \mathrm{C}$ ou coliformes fecais (TT): são um sub-grupo dos coliformes totais que apresentam a capacidade de continuar fermentando lactose com produção de gás, quando incubadas a temperaturas de 44,5 a $45,5^{\circ} \mathrm{C}$ em 24 horas $^{(8)}$; c) Pesquisa de Escherichia coli, esta faz parte dos coliformes totais e termotolerantes e pode ser diferenciada dos demais coliformes pelo crescimento característico em ágar seletivo e pelo padrão bioquímico obtido nos testes INViC (produção de indol, vermelho de metila, VogesProskauer e citrato). Embora sua presença não indique necessariamente uma origem fecal é considerada um indicador das condições de higiene, principalmente em alimentos in natura ${ }^{(8,9)}$.

As análises microbiológicas foram realizadas conforme os métodos analíticos oficiais do Ministério da Agricultura, Pecuária e Abastecimento, $\operatorname{MAPA}^{(11)}$, resumidamente:

a) NMP de coliformes totais (CT) e Termotolerantes a $45^{\circ} \mathrm{C}$ (TT) As amostras foram homogeneizadas em agitador tipo vortex e submetidas a três diluições decimais seriadas. De cada uma das diluições, alíquotas iguais foram transferidas para três tubos contendo o meio de cultura apropriado e um tubinho de Durhan (tubo coletor de gás). Assim, a partir de cada tubo positivo para CT (turvação do caldo de cultura LaurilSufatoTriptose e formação de gás no tubinho Durhan) semeou-se uma alíquotapara tubos contendo caldo Verde Brilhante (VB) e uma alíquota para tubos contendo caldo EC. No caldo VB confirmou-se a presença de coliformes totais $\left(35^{\circ} \mathrm{C}\right)$ e no caldo EC $\left(44,5^{\circ} \mathrm{C} \pm 0,5^{\circ} \mathrm{C}\right)$ a presença de coliformes Termotolerantes a $45^{\circ} \mathrm{C} / \mathrm{g}$ de alimento. O NMP por grama de produto foi determinado pelo número de tubos positivos em cada diluição. Para tal determinação utilizou-se a tabela estatística de NMP para três tubos ${ }^{(13)}$.

b) Pesquisa de Escherichia coli: a partir dostubos positivos para Termotolerantes a $45^{\circ} \mathrm{C}$, alíquotas foram semeadas por estrias em ágar seletivo Eosina azul de metileno (EMB), de modo a obter colônias isoladas. Incubou-se a $35^{\circ} \mathrm{C}$ durante 24 horas e observaram-se colônias típicas de E.coli(de coloração negra com brilho metálico esverdeado). Procedeu-secom a confirmação bioquímica das colônias suspeitas em Agar EMB. Os resultados foram expressospelas contagens de coliformes totais e coliformes a $45^{\circ} \mathrm{C}$ em 
ZANONI, K.; GELINSKI, J. M. L. N. Revista Eletrônica de Farmácia Vol. X (3), 30 - 42, 2013.

NMP por grama de alimento e presença ou ausência de E.coli;

c) Pesquisa de Salmonellaspp:a partir de uma cultura de enriquecimento das amostras em caldo Tetrationato e caldo RapapportVassiliadis foram semeadas alíquotas em placas de ágaresseletivos (ágar Xilose Lisina Deoxicolatoe Ágar Bismuto sulfito) de modo a obter colônias isoladas. Incubou-se a $35-37^{\circ} \mathrm{C}$ por 24 horas. Identificaram-se as colônias suspeitas seguindo-se de identificação bioquímica. Os resultados foram expressos como ausência ou presença de Salmonellaem $25 \mathrm{~g}$ de alimento.

A análise dos resultados também foi baseada no que preconiza a legislação vigente da Anvisa na RDC n.12 de 02.01.2001 $1^{(11)}$.

\section{RESULTADOS E DISCUSSÃO}

Como o cardápio diário de opções de salada de verduras de cada restaurante analisado variava, optou-se por analisar o conjunto de verduras cruas disponíveis no dia em cada um deles. Portanto, os resultados das análises microbiológicas abrangem $\mathrm{o}$ perfil higiênico do conjunto de cada amostra (salada) ainda que algumas ou todas as verduras de cada conjunto pudessem estar livres de contaminação.

$\mathrm{Na}$ Tabela 1 apresentam-se os resultados das análises microbiológicas realizadas com as amostras de verduras (salada) obtidas de cada um detrês restaurantes tipo self service. Verifica-se que os coliformes totais estiveram em número bastante alto em pelo menos duas das análises para os três restaurantes. Os coliformes fecais (Termotolerantes a $45^{\circ} \mathrm{C}$ ) estiveram acima do limite preconizado pela legislação (11) em pelo menos duas análises para os restaurantes B e C.

O restaurante $A$ que se localiza em um bairro da periferia da cidade serve também café da manhã e jantar. As saladas de vegetais dispostas no final do buffet são acondicionadas em pratos grandes de vidro e sem refrigeração. Localizado na região central, o restaurante $B$, serve almoço diariamente e o buffeté constituído de pratos quentes e frios e as saladas de vegetais estão dispostas separadamente dos demais pratos. São acondicionadasem grandes bandejas de alumínio sem refrigeração. Já o restaurante $C$, também localizado

Tabela 1. Resultados das análises microbiológicas conforme Número Mais Provável Série 3 tubos $(\mathrm{NMP} / \mathrm{g})$ 
ZANONI, K.; GELINSKI, J. M. L. N. Revista Eletrônica de Farmácia Vol. X (3), 30 - 42, 2013.

\begin{tabular}{|c|c|c|c|c|c|c|c|c|c|c|c|c|c|}
\hline \multirow{3}{*}{$\begin{array}{c}\text { Restaurantes } \\
\text { NMP/g } \\
\end{array}$} & \multicolumn{3}{|c|}{ A } & \multicolumn{5}{|c|}{ B } & \multicolumn{5}{|c|}{ C } \\
\hline & \multicolumn{3}{|c|}{ Coliformes } & \multicolumn{4}{|c|}{ coliformes } & \multirow[t]{2}{*}{ SAL } & \multicolumn{3}{|c|}{ Coliformes } & \multirow[t]{2}{*}{ SAL } & \multirow{2}{*}{$\begin{array}{c}\begin{array}{c}\text { Limites } \\
\text { Maximos* }\end{array} \\
\text { Termoto- }\end{array}$} \\
\hline & $\mathrm{CT}$ & TT & $\mathrm{EC}$ & & $\mathrm{CT}$ & TT & $\mathrm{EC}$ & & $\mathrm{CT}$ & TT & $\mathrm{EC}$ & & \\
\hline Analise 1 & 460 & 3 & aus & aus & $>1100$ & $<3,6$ & aus & aus & $>1100$ & $<3,6$ & aus & aus & lerantes a \\
\hline Análise 2 & 460 & 75 & aus & aus & $>1100$ & $>1100$ & aus & aus & 150 & 290 & aus & aus & $45^{\circ} \mathrm{C}=100$ \\
\hline Analise 3 & $>1100$ & 3,6 & aus & aus & 240 & 3,6 & aus & aus & $>1100$ & $<3,6$ & aus & aus & Escherichia \\
\hline Análise 4 & $>1100$ & $<3,6$ & aus & aus & 290 & $<3,6$ & aus & aus & $<3,6$ & $<3,6$ & aus & aus & coli $=$ aus \\
\hline Análise 5 & $<3,6$ & $<3,6$ & pres & aus & $<3,6$ & $<3,6$ & aus & aus & $<3,6$ & $<3,6$ & aus & aus & \\
\hline
\end{tabular}

na região central da cidade, distribui o buffet começando pelas saladas, que são colocadas em pratos de vidro grande, sem refrigeração.

A presença de Escherichia coli foi confirmada em uma das amostras para o restaurante. No presente estudo não foi detectada a presença de Salmonellaspp. em nenhuma das amostras em todos os restaurantes. Embora isto seja um fato positivo,a não detecção do patógeno pode ser explicada devido ao alto número de coliforme totais e fecais, que podem ocasionar a inibição do patógeno em relação à microbiota presente de coliformes totais, em geral mais abundante em alimentos com higienização inadequada ${ }^{(7)}$. Resultado semelhante ao desta pesquisa foi encontrado por Santos et.al. ${ }^{(14)}$ quando avaliaram apenas um tipo de verdura, a alface e não detectaram a presença de Salmonella spp.. Shinoharaet al. ${ }^{(7)}$ avaliaram estudos indicando que muitos alimentos podem ser contaminados por Salmonella, como carnes, leite e derivados e ovos, sendo que a contaminação ocorre principalmente, devido ao controle inadequado da temperatura e de práticas de manipulação incorretas, portanto falta de rigor na vigilância sanitárias dos alimentos.As frutas e vegetais com alta atividade de água,também podem transmitir salmonelosee, quando postas para consumo in naturatambém necessitam de um processo rigoroso de higiene e manipulação.

Nos três restaurantes observou-se que as saladas de vegetais não estavam frescas, mas, à disposição no balcão de serviço há pelo menos duas horas. A reposição das saladas era feita pelos manipuladores dos alimentos e as mesmas eram levadas em pratos de vidro e colocadas junto as que já estavam na mesa do self service.

No estudo da ocorrência de enteroparasitas em hortaliças comercializadas na região metropolitana de São Paulo, SP,Oliveira e Germano(15) avaliaram que a forma física das hortaliças contribuiu para uma diferença nos níveis de contaminação observada nas amostras de alface lisa e crespa, escarola e agrião. Segundo os autores, 
ZANONI, K.; GELINSKI, J. M. L. N. Revista Eletrônica de Farmácia Vol. X (3), 30 - 42, 2013.

isto pode ser aplicado aos valores encontrados para o agrião, que se mostraram significativamente maiores em relação às outras hortaliças. Em estudo semelhante realizado na cidade de Florianópolis, SC, Soares eCantos ${ }^{(16)}$ concluíram que os principais fatores envolvidos na contaminação das verduras foram a origem das águas de irrigação, o acondicionamento, o transporte e a manipulação destas durante a coleta.

No presente estudo observou-se que no restaurante $B$, onde foram coletadas mais amostras de vegetais folhosos em relação aos outros dois restaurantes, os resultados de contaminantes são realmente maiores, reforçando que a forma física dos vegetais pode sim estar associada a um nível maior de contaminação (Quadro1, Tabela 1).

Estudo realizado por Correa et al. ${ }^{(17)}$ permitiu avaliar a eficiência na redução do NMP de coliformes termotolerantes pela lavagem e uso de desinfetantes em vegetais frescos com soluções de hipoclorito de sódio (200ppm/15min.), vinagre (10\%/5min), permanganato de potássio (25ppm/7min) e um produto comercial para desinfecção de vegetais (10 gotas/1L de água/10 min.). Verificou-se que 0 hipoclorito de sódio foi 0 desinfetante com maior eficiência.

Considerando os resultados obtidos no presente estudo pode-se considerar que os restaurantes poderiam realizar de forma rotineira a lavagem com o hipoclorito de sódio, pois é uma medida simples, de baixo custo e rápida.

Ameko et al. (18) analisaram vegetais frescos comercializados em feiras livres em um municipio de Ghana, na Africa e verificaram que a contagem bacterianaemalface excedeu o recomendado pela OrganizaçãoMundial deSaúde(WHO) e pelaComissão Internacional

deespecificaçõesmicrobiológicaspara alimentos (ICMSF) ou seja, de que a contagem deve ser no máximo igual a $10^{3} \mathrm{UFC} / \mathrm{g}$ para bactérias aeróbias totais. Esse estudo englobava ainda outros tipos de vegetais e alimentos crus servidos sem qualquer preocupação com uma higienização eficiente, limitando-se apenas à lavagem dos alimentos em água corrente para retrada de sujidades grosseiras. Assim, pode-se deduzir que a falta de uma higienização adequada é um problema que vai além fronteiras. Daí o porque de a contaminação e quantidade de surtos mundiais por doenças transmitidas por alimentos ainda ser motivo de discussão mundial ${ }^{(19)}$.

Nos estudos de Soares e Cantos ${ }^{(16)}$ e de Takayanaguiet al. ${ }^{(20)}$ realizados em Florianópolis SC e Ribeirão Preto SP, respectivamente, há um consenso quanto a necessidade de atividades educativas para os manipuladores $e$ consumidores de alimentos. Ambos os estudos concluíram que sucessivas manipulações aumentam as chances de 
ZANONI, K.; GELINSKI, J. M. L. N. Revista Eletrônica de Farmácia Vol. X (3), 30 - 42, 2013.

contaminação nas hortaliças. Além disso, no estudo realizado por Coelho et al. ${ }^{(2)}$, foram observadas altas contagens em superfícies de bancadas, utensílios e equipamentos nos restaurantes avaliados. De acordo com os autores, $71 \%$ dos equipamentos e $85,7 \%$ dos utensílios estavam inadequados. Contagens maiores foram registradas nas bancadas de preparo de vegetais e de carnes. Considerando os resultados obtidos na presente pesquisa é possível afirmar que o risco de contaminação cruzada também pode estar ocorrendo nos restaurantes avaliados, pois os utensílios e equipamentos são comuns a esses estabelecimentos.

Com base nos padrões microbiológicos vigentes da RCD no 12 de 02.01.2001 da ANVISA $^{(13)}$, as saladas de vegetais foram consideradas impróprias para consumo e, de acordo com 0 artigo 20 que aprova 0 regulamento técnico sobre padrões microbiológicos para alimentos, o descumprimento aos termos desta resolução, constitui infração sanitária, sujeitando os infratores às leis e demais disposições aplicáveis.

\section{CONCLUSÃO}

Para os três restaurantes analisados quanto à oferta de saladas de vegetais servidas verificou-se que os mesmos não apresentaram total segurança alimentar, visto que todos evidenciaram resultados não conformes à legislação vigente. Considerando esses resultados, é possível afirmar que houve falta de higiene nos três restaurantes e que medidas de controle devem ser adotadas imediatamente, diminuindo assim o risco

de transmissão de DTA's pelos consumidores daqueles estabelecimentos.A contaminação pode ocorrer em diversas etapas de preparo das refeições, por isso, torna-se importante a adoção de boas práticas de higiene nos restaurantes avaliados.

Portanto, também é importante que haja intensificação da fiscalização em restaurantes self serviceno município estudado, bem como campanhas de práticas educativas para treinamento de pessoal dos manipuladores de alimentos.Programas de reeducação alimentar para os consumidoresvisando auxiliar a toda a população da importância de ficar atentos ao consumo de alimentos frescos e de qualidade também seriam importantes.

\section{Agradecimentos}

Ao fundo de Apoio a Pesquisa da Universidade do Oeste de Santa Catarina.

\section{REFERÊNCIAS}


ZANONI, K.; GELINSKI, J. M. L. N. Revista Eletrônica de Farmácia Vol. X (3), 30 - 42, 2013.

1. ChoumanK,Ponsano EHG, Michelin AF de. Qualidade microbiológica dos alimentos servidos em restaurantes self-service. RevInst Adolfo Lutz (Impr.), [Internet]. 2010;69(2):261-2660http://periodicos.ses.sp.bvs.br/pdf/rial/v69n2/v69n2a18.pdf

2. CoelhoAIM, Contaminação microbiológica de ambientes e de superfícies em restaurantes comerciais. Ciênc. saúde coletiva. [Internet]. 2010;15 (1 suppl):15971606.Availablefrom: http://www.scielo.br/pdf/csc/v15s1/071.pdf

3. BaruffaldiR, Penna TCV, MachoshviliIA, Abe LE. Tratamento químico de hortaliças poluídas. Rev SaúdePública. [Internet]. 1984[cited 2012 nov 22];18(3):225-234. Available at:http://www.rsp.fsp.usp.br/mensagem/pub/busca.tpl.php

4. Lima JX,Oliveira LF. O crescimento do restaurante self-service: aspectos positivos e negativos para o consumidor. HigAliment. 2005;19(128):45-53.

5. Pinto UM,Cardoso RR, Vanetti MCD. Detecção de Listeria, Salmonella e Klebsiellaem serviço de alimentação hospitalar. Rev Nutr. [Internet]. 2004 [cited 2012 nov 21];17(3):319-326.

Available from: http://www.scielo.br/pdf/rn/v17n3/21881.pdf.

6. Carmo GMI do, Oliveira AO, dos Santos DA, Almeida MG, Berto LH, Alves RMS, Carmo EH. Vigilância epidemiológica das doenças transmitidas por alimentos no Brasil, 1999-2004.Boletim Eletronico Epidemiológico.Secretaria de Vigilância em Saúde. [Internet]. 2005 [cited 2012 nov 21];5(6):1-6. Availablefrom: http://bvsms.saude.gov.br/php/level.php?lang=pt\&component=44\&item=126

7. Shinohara NKS, et al. Salmonella spp., importante agente patogênico veiculado em alimentos. Ciênc. saúde coletiva, [Internet]. 2008 [cited 2012 ago30]; 13(5):6691674 2008. Availablefrom: http://www.scielo.br/pdf/csc/v13n5/31.pdf

8. Silva N, Junqueira VCA, Taniwaki MH, Santos RFS dos, Gomes RAR. Manual de métodos de análise microbiológica de alimentos. 3th ed. São Paulo: Editora Varela, 2007.

9. FrancoBDGM. Microbiologia dos alimentos. 2nd ed. São Paulo: Editora Atheneu, 2003.

10. BRASIL. Ministério da Saúde - Secretária de vigilância em saúde. COVEH/CGDT/DEVEP/SVS/MS. Análise epidemiológica dos surtos de doenças 
ZANONI, K.; GELINSKI, J. M. L. N. Revista Eletrônica de Farmácia Vol. X (3), 30 - 42, 2013.

transmitidas por alimentos no Brasil, 1999-2009*. [Internet]. 2009 [cited 2012 out 20]. Available from:

http://www.google.com.br/url?sa $=t \& r c t=j \& q=\& e s r c=s \& f r m=1 \&$ source $=$ web\&cd $=2 \& s$ qi=2\&ved=0CDcQFjAB\&url=http $\% 3 \mathrm{~A} \% 2 \mathrm{~F} \% 2 \mathrm{Fportal}$.saude.gov.br\%2Fportal\%2Farqui vos\%2Fpdf\%2Fanalise ep surtos dta brasil 2009.pdf\&ei=8Y3PULS5FtDOqAHzICYCA\&usg=AFQjCNHlijxVNeD5oHvngMshnA7Uyoq85A.

11. BRASIL. Ministério da Saúde - Agência Nacional de Vigilância Sanitária. ResoluçãoRDC $\mathrm{n} .12$ de 02 de janeiro de 2001. Aprova o Regulamento sobre padrões microbiológicos para alimentos. Available from: http://www.anvisa.gov.br/legis/resol/10 01rdc.htm

12. BRASIL. Ministério da Saúde - Agência Nacional de Vigilância Sanitária. ResoluçãoRDC n.12 de 02 de janeiro de 2001. Aprova o Regulamento sobre padrões microbiológicos para alimentos. Available from: http://www.anvisa.gov.br/legis/resol/10 01rdc.htm

13. Blodgett R. FDA/BAM. Bacteriological Analytical Manual. Most Probable Number from Serial Dilutions. Bacteriological Analytical Manual, 8th Edition, Revision A, 1998. Available from:http://www.fda.gov/Food/ScienceResearch/LaboratoryMethods/BacteriologicalA nalyticalManualBAM/ucm 109656.htm

14. Santos, LC dos, Faria, LA de, Simm, EM,Bechtlufft, M de P. Avaliação da qualidade microbiológica da alface (Lactuca Sativa), comercializada na cidade de Pará de Minas, MG.HigAlim. 2011;25(194/195):148-152

15. Oliveira CAF de; Pedro Manuel Leal Germano ${ }^{\text {II }}$. Estudo da ocorrência de enteroparasitas em hortaliças comercializadas na região metropolitana de São Paulo, SP, Brasil. I - Pesquisa de helmintos. RevSaúde Pública. [Internet]. 1992 [cited 2012 nov 22];26(4):283-9. Available from:

http://www.scielo.br/scielo.php?script=sci_arttext\&pid=S0034-

$89101992000400011 \&$ lng $=p t \& n r m=i s o>$. ISSN 0034-8910.

http://dx.doi.org/10.1590/S0034-89101992000400011 
ZANONI, K.; GELINSKI, J. M. L. N. Revista Eletrônica de Farmácia Vol. X (3), 30 - 42, 2013.

16. Soares B, Cantos GA. Qualidade parasitológica e condições higiênico sanitárias de hortaliças comercializadas na cidade de Florianópolis, Santa Catarina, Brasil. RevBrasEpidemiol. 2005;8(4):377-84.

17. Corrêa, TAF; Silva, MG da, Balestrin, EC do, Rall, VLM. Eficiência da lavagem edos desinfetantes sobre coliformes termotolerantes em vegetais frescos. HigAlim. 2011;25(194/195):154-157.

18. Ameko E, Achio S, A, Alhassan S, KassimA. Microbial safety of raw mixed-vegetable salad sold as an accompaniment to street vended cooked rice in Accra, Ghana. African Journal of Biotechnology[Internet]. 2012 [cited 2012 jun 21];11(50):1107885. Available from: http://www.academicjournals.org/Ajb/PDF/pdf2012/21Jun/Ameko\%20et\%20al. pdf

19. WHO - WORLD HEALTH ORGANIZATION. WHO Initiative to Estimate the Global Burden of Foodborne Diseases. A summary document [Internet]. 2012 [cited 2012 jun 21]. Available from: http://www.who.int/foodsafety/foodborne disease/en/

20. Takayanagui OM, OliveiraC, BergaminiAMM,Capuano DM,OkinoMHT, Febrônio LHP, et al. Fiscalização de verduras comercializadas no município de Ribeirão Preto, SP. Revista da Sociedade Brasileira de Medicina Tropical [Internet]. 2001 [cited 2012 nov 23];34(1):37-41. Available from: http://www.scielo.br/pdf/rsbmt/v34n1/4316.pdf 